\title{
AS AÇÕES DOS TRABALHADORES NO CAMPO DA QUALIFICAÇÃO PROFISSIONAL EM RECIFE (1889-1930)
}

\author{
Yan Soares Santos Correio ${ }^{1}$ \\ Ramon de Oliveira Correio ${ }^{2}$
}

\section{RESUMO}

Objetivando analisar as práticas de empregadores e trabalhadores do Recife voltada às ações de qualificação profissional entre os anos de 1889 e 1930, investigou-se nos arquivos da Fundação Joaquim Nabuco (FUNDAJ) e no arquivo Público Estadual Jordão Emerenciano, documentos referentes às demandas e ofertas de mão-de-obra em Recife e levantou-se a documentação produzida pelas associações patronais e de trabalhadores, neste período. Analisando a Associação dos Empregados no Comércio de Pernambuco, constatou-se que a partir das condições insalubres de trabalho, da disputa por mercado, da falta de reconhecimento social e impossibilidade de subsistir e subvencionar custos básicos individuais, os trabalhadores organizaram-se em associações, as quais através de ações no ensino profissional protegeram e tentaram monopolizar a oferta de certos serviços profissionais. Constatando-se assim que os principais responsáveis pela qualificação dos trabalhadores foram as suas associações corporativas. Tais descobertas nos levam a concluir que o processo de preparação para o trabalho representava muito mais que apenas um movimento de qualificar o trabalhador, configurava-se como um ato sócio-político de fortalecimento de categorias profissionais.

Palavras-chave: Associativismo; Qualificação Profissional; Recife; Trabalhadores; História da Educação.

\section{ACTIONS OF WORKERS IN THE FIELD OF PROFESSIONAL QUALIFICATION IN RECIFE (1889-1930)}

\begin{abstract}
Aiming to analyze the habits of employers and workers in Recife related with professional qualifications between the years 1889 and 1930, it was investigated archives of the Joaquim Nabuco Foundation (FUNDAJ) and the Emerenciano Jordan State Public File (APEJE). It was collected documents relating to demands and offers of jobs in Recife and documentation produced by the associations of employers and workers. Analyzing the Commerce Employees Association of Pernambuco, it was found that from unhealthy work conditions, the competition for the market, the lack of social recognition and inability to stand and subsidize basic costs individual workers organized themselves in associations. Through this associations the workers carried out several qualification initiatives and attempted to monopolize the provision of certain professional services. Noting up so that the primary responsibility for worker skills were their corporate associations. These findings lead us to conclude that the process of preparation for the work represented more than just a move to qualify the worker, configured to act as a socio-political empowerment of professional categories.
\end{abstract}

Keywords : Associations; Professional Qualification; Recife; Workers; History of Education. 


\section{Introdução}

Em pesquisa (OLIVEIRA, 2011) interessada na qualificação profissional no século XIX, constatou-se que o processo de industrialização pernambucano, naquele período, foi muito lento e não houve a necessidade de nenhuma ação do poder público de forma a garantir uma mão-de-obra adequada às novas necessidades. Muito pelo contrário, se olharmos os dados referentes à taxa de escolarização e os índices de analfabetismo veremos que o Recife e toda a província de Pernambuco apresentavam uma população com baixa qualificação, mesmo aquela referente ao domínio da leitura e da escrita.

No entanto, não se deixa de reconhecer que havia um discurso estatal em defesa de maior investimento em educação, bem como o interesse em construir espaços voltados ao processo de instrução profissional.

Constatou-se não ter existido nenhuma ação pública direta na formação profissional, exceto os asilos de órfãos. Essas ações quando existiam ocorriam via alguma parceria com algum empresário ou alguma entidade da sociedade, como foi aconteceu com a Sociedade dos Artistas Mecânicos e Liberais, a qual resultou na construção do Liceu de Artes e Ofícios, em 1880.

A pesquisa deixou evidenciado o fato de que na segunda metade do século XIX não surgiram cobranças por parte dos patrões de habilidades novas por parte dos trabalhadores. Nem sequer cobrança do domínio da leitura e da escrita aparece em número expressivo nos anúncios dos jornais.

A inexistência de um processo de industrialização, a manutenção de relações de exploração intensa da mão-de-obra, a abundância de uma mão-de-obra barata, parecem ter contribuído para que, embora na segunda metade do século XIX tenha sido rico o debate sobre a importância do investimento na educação e na importância da instrução profissional para o desenvolvimento econômico da província de Pernambuco, esses debates não tenham se materializado em ações concretas do poder público.

Tendo essa interpretação a partir da pesquisa realizada, acreditamos ser pertinente que após a proclamação da República e a chegada do século XX, comecemos a ver um movimento de práticas de patrões, trabalhadores e Estado, voltadas para ações concretas de qualificação profissional.

Com a proclamação da república e o fim da escravidão, iniciou-se uma lenta modificação do quadro econômico do estado de Pernambuco. Para ter uma ideia dessas mudanças, Fonseca (1986) destaca que, ao término do Império, Pernambuco apresentava um número muito pequeno de indústrias. No entanto, com o advento da República esse cenário sofreu uma profunda modificação. Em 1910, com o total de 118 estabelecimentos industriais, esse Estado já ocupava a sétima posição entre os que apresentavam maior número de indústrias. Já no correspondente ao número de trabalhadores no setor industrial, a posição pernambucana era um pouco melhor: quinto lugar. Somando um total de 12.042 trabalhadores.

Tendo esse cenário como referência, apresentaremos nesse texto as primeiras aproximações da análise dos mecanismos de qualificação profissional desencadeado pela sociedade civil visando atender às necessidades da economia e da urbanização recifense entre os anos de 1889 e 1930, mais particularmente destacaremos as ações da Associação dos Empregados no Comércio de Pernambuco.

Enquanto fontes utilizadas nessa investigação, destacamos os anúncios do Diário de Pernambuco de demanda e oferta de trabalhadores entre os anos de 1889 e 1930, coletados na Fundação Joaquim Nabuco e o material coletado no Arquivo Público Estadual Jordão 
Emerenciano (APEJE): os códices Folhetos Raros II, Impressos Particulares e Petições. Além de uma série de documentos referentes a associações de trabalhadores, patrões e sociedade civil, fotodigitalizando um total de 1921 folhas referentes a esses documentos.

\section{Aspectos gerais do Recife}

O período compreendido entre 1889 e 1930 tem a singularidade de ser aquele no qual se demarca o início do processo de industrialização brasileira. Como destaca Prado Júnior (1973), as modificações ocorridas no plano econômico e político brasileiro, tais como a abolição da escravidão, o fim da monarquia, a abertura para mão-de-obra imigrante, junto a outros fatores, foram responsáveis pela criação das condições para o Brasil continuar inserido na divisão internacional do trabalho. Ou seja, segundo Prado Júnior, o industrialismo brasileiro foi também expressão da emergência de uma nova cultura econômica no início do século XX.

Celso Suckow da Fonseca (FONSECA, 1986a) nos chama atenção para o fato de que com a chegada do século XX não se registrou apenas um aumento de fábricas e de operários, mas, fundamentalmente, necessidades mais complexas por parte das indústrias em função da mecanização crescente no processo de produção. Tal fato, segundo este autor apontava para a necessidade de ampliar/implantar o ensino profissional.

Diversos autores, de acordo com a análise de Bernardes (1996), destacam que o crescimento espacial e populacional da cidade do Recife ocorreu, desde fins do século XIX, sem um correspondente aumento no nível da oferta dos empregos demandados pelos contingentes de trabalhadores que, crescentemente, se deslocavam do campo para a cidade.

Singer (1977) destacou que a primeira onda de industrialização do Recife ocorreu a partir de 1875 e esteve voltada para os bens de consumo duráveis e concentrada nos principais bairros da cidade, como Santo Amaro, Boa Vista, Várzea, e também em bairros adjacentes como Cordeiro, Macaxeira e Torre, sobretudo a indústria têxtil. Impulso insuficiente para imprimir um ritmo próprio às atividades urbanas, aumentar a oferta de trabalho e superar a centralidade das atividades agroexportadoras. Pernambuco contava no ano de 1907 com apenas 72 fábricas, nas quais trabalhavam 7.155 operários e em 1920 já contava com 442 fábricas e tinha dobrado a quantidade de trabalhadores nelas empregados, 15.761 no total (DIRETORIA, 1920a).

De acordo com a estatística populacional e industrial, Pernambuco era o quinto Estado mais populoso do país com um total de 841.539 no ano de 1872 , subindo para 1.030.256 em 1890, chegando a 2.154.835 em 1920, precedido apenas por Minas Gerais, São Paulo, Bahia e Rio Grande do Sul (do primeiro ao quarto mais populoso).

A cidade de Recife em 1872 contava com 111. 556 pessoas, subindo para 113.106 em 1890 e alcançando em 1900 um total de 116.671 pessoas, o que correspondia a cerca de $16 \%$ do total populacional do Estado (FUNDAÇÃO, 1990)

Dentre os aspectos econômicos da cidade do Recife, Barbosa (2008) apresenta algumas tabelas com as quais podemos dialogar. De acordo com esses dados, Pernambuco no ano de 1920 aparece com um total de 606.088 trabalhadores, subdivididos em diversos setores. O que mais empregava trabalhadores era a agricultura com 475.653 (78\% do total) seguida logo pela indústria com 70.313 (12\% do total). Já em Recife havia um total de 238.843 trabalhados (39\% dos trabalhadores do Estado), destacando-se a agricultura com 13.501 trabalhadores e a indústria com 26.230 operários.

Já nas estatísticas de imóveis dedicados a atividade econômica, um relatório de 1920 indicava que Recife contava com 3.211 prédios, no qual aproximadamente $75 \%$ 
desses prédios eram ligados à atividade comercial e apenas $17 \%$ para a atividade industrial (DIRETORIA, 1920b).

Para o censo escolar que compreende os anos de 1907 a 1912 fez-se um balanço do ensino profissional nos diversos Estados. Pernambuco contava em 1907 com escolas nas modalidades de ensino profissional: sacerdotal, pedagógico, artístico liberal, artístico industrial, agronômico e comercial.

O ensino sacerdotal, empregado por instituições religiosas voltadas para desvalidos, contava com uma média de 6 prédios escolares, envolvendo 31 docentes; o profissional pedagógico, voltado para a formação para o magistério, contava com escolas abertas pelo Estado ou por particulares somando um total de 4 prédios, com 68 professores e atingindo um total de 577 matrículas em 1912.

Já o ensino profissional artístico liberal contou com uma escola aberta por particulares, envolvendo 4 docentes e um total de 28 matrículas, no ano 1909.

O ensino artístico industrial contava com 4 escolas particulares, 42 docentes e um total de 1.103 matrículas em 1907.

O ensino profissional agronômico também era de empreitada particular alcançando em média 4 escolas, com 28 docente em 1912 e um total de 94 matrículas que chegava a 94 alunos.

Por fim o ensino profissional comercial contava com apenas uma escola particular, envolvendo 3 docentes e atingindo 12 matrículas (Diretoria, 1927. pp. 930-1.037).

A estatística escolar publicada em 1916 nos informa que o Estado de Pernambuco, em 1907, contava com 651 escolas e 667 cursos, com 34.200 alunos, numa média de 53 alunos por escola e 51 por curso. No entanto, dos cursos ofertados, 639 eram primários; 16 secundários, dois eram de ensino superior e havia apenas 10 cursos profissionais, demonstrando que apesar da tentativa de implementar o ensino profissional ainda era pequena a oferta desses cursos pelos agentes públicos (Diretoria, 1916).

Neste ínterim, temos um Recife reminiscente de revoltas populares ditas liberais; episódios antilusitanos; uma política voltada para os melhoramentos materiais da província, tais como a melhoria do porto, implementação de fábricas, melhorias dos engenhos centrais para as usinas de açúcar, estradas de ferro, água encanada, esgotamento sanitário, e preocupação com a higienização pública; em um contexto de longos períodos de secas e de migrações do campo para a cidade (CARVALHO, 1998; MELLO, 1999; ARRAIS, 2004). A cidade de Recife apresentava bastante dinamicidade e propícia para vicissitudes sociais, onde as transformações no aspecto econômico e urbano poderiam modificar as relações de trabalho, bem como o desaparecimento de algumas profissões, como, por exemplo, os canoeiros responsáveis por todo o transporte fluvial recifense até a segunda metade do século XIX (MELLO, 1978).

Nesse contexto, como eram demandados esses trabalhadores? Buscamos então nos Anúncios Diversos do Diário de Pernambuco entre os anos de 1889-1930 os registros dessas demandas de trabalhadores e percebemos que prevaleciam os pedidos por amas (ofício relacionado ao trabalho doméstico) e caixeiros (ofício voltado para as atividades comerciais em diversos campos de atuação que vai de pequenas lojas, boticas e mercearias até a guarda-livros e escriturários).

Os anúncios demandando trabalhadores para a agricultura, para a indústria, ou para profissionais liberais e serviços em geral não chegaram a $15 \%$ dos anúncios coletados.

Destacados aspectos gerais do mercado de trabalho recifense na Primeira República, nos voltaremos para os achados sobre as ações dos próprios trabalhadores voltadas para a qualificação profissional. 


\section{Associativismo e qualificação profissional: as ações dos trabalhadores}

Durante a pesquisa encontramos no Arquivo Público Estadual Jordão Emerenciano documentos de associações beneficentes e mutualistas instauradas na cidade do Recife que se preocuparam dentre diversas questões com o ensino profissional. Desde o fim das corporações de ofício em 1824, o associativismo foi o meio pelo qual os trabalhadores se organizavam e pugnavam pelos seus direitos, bem como instruíam novos trabalhadores no ofício referente à associação. Para funcionarem era necessário que os estatutos fossem aprovados pelos poderes públicos (MAC CORD, 2009). Das 28 associações, 8 tinham essa preocupação (ensino profissional) destacada em seus estatutos e em seus relatórios anunciavam o andamento desses cursos.

Essa preocupação com a formação dos trabalhadores expressava-se por meio da abertura de cursos e entendia-se que a qualificação/instrução dos associados renderia a eles o monopólio de mercado, sendo empregados apenas aqueles que possuíam qualificação e, futuramente, o diploma das matérias cursadas.

De acordo com Gondra e Schueler (2008), as associações tais como essas que pesquisamos, são espaços de sociabilidade, de socialização de saberes e de propostas de auxílio mútuo e beneficente. Elas estavam envolvidas com o processo educativo, mas também pensaram na civilidade como uma proposta estatutária, visando civilizar os associados como um bem à nação, discurso utilizado pelos próprios trabalhadores a fim de ter a permissão dos poderes públicos para fundar a associação (MAC CORD, 2011).

Pela sistematização feita a partir dos trabalhos de Batalha $(1999,2004,2006)$, que a partir da História Social do Trabalho apresenta como os trabalhadores pelas suas experiências vivenciavam relações entre si, com a população, patrões e poderes públicos em fins do século XIX e da Primeira República, identificamos nas associações pesquisadas algumas características comuns:

1. Condição para a associação: exercer o ofício da associação ou semelhante atividade. $\mathrm{Ou}$ ainda ser um indivíduo prestativo à associação ou merecedor dos préstimos da sociedade (apesar de algumas associações terem sócios de ofícios não comuns à associação);

2. Prestação de auxílio aos sócios: por meio da cobrança de fundos sociais, como as mensalidades e as joias; ofertavam-se alguns serviços como o auxílio funeral, pensão familiar para falecimento do sócio e pensão por invalidez;

3. Educação para uma qualificação profissional;

5. Controle e proteção contra a concorrência do mercado de trabalho;

4. Melhor condição de trabalho dos qualificados, quanto à renda, à regularidade e à estabilidade no emprego; condições de moradia; proteção legal e à saúde; condições de negociação mais fortes com o patrão (talvez devido à oportunidade de poderem associarse);

5. Caráter de reivindicação político-trabalhista: aumento de salários e diminuição de horas de trabalho.

As associações dependiam das experiências vividas pelos trabalhadores, principalmente em virtude da impossibilidade de arcarem sozinhos com despesas cotidianas, sejam aquelas voltadas para a proteção profissional, para garantir uma educação profissional ou mesmo objetivando fortalecer-se no âmbito de suas reivindicações políticotrabalhistas. 
A análise dessas associações nos permitiu concluir que foram os trabalhadores os maiores preocupados com a qualificação profissional, visto não ter havido por parte do Estado uma mobilização maior visando abrir escolas para qualificar os trabalhadores.

Algumas associações determinavam que só pudessem ser empregados os trabalhadores portadores de um diploma expedido pela sociedade do ofício específico. Um bom exemplo deste ato específico foi a Associação dos Empregados no Comércio de Pernambuco.

Não foi possível na pesquisa identificar o estatuto que deu início as atividades da associação, no entanto no primeiro registro datado do ano de 1892, observa-se logo em seu primeiro artigo o interesse da associação de: "reunir em um grêmio fraternal os empregados no mesmo comércio protegê-los e as suas famílias, instruí-los e pugnar pelos interesses legítimos de cada um deles e pelos da classe em geral, empregando os recursos a seu alcance" (ESTATUTOS, 1892. p. 3).

Havia o interesse dos associados em fazerem da associação um meio para auxílios políticos, onde pugnar (leia-se: tomar a defesa) pelos interesses legítimos representava uma necessidade ou princípio da categoria em geral e não apenas a satisfação de um interesse particular.

A proteção destacada é a financeira, em caso de doenças, invalidez (destinada ao sócio) ou em caso da morte deste, a beneficência à sua família. E por fim, de acordo com este estatuto, a necessidade de instruir os associados.

Mas como seria essa instrução? Ocorria um ensino de matérias necessárias à instrução comercial e ministradas num curso noturno, abrindo espaço para a abertura de novas cadeiras, mas para isso era preciso que as mesmas fossem reclamadas por vinte sócios no mínimo.

Tais aulas seriam ministradas por professores contratados ou não, sendo pertencentes ou não à associação, sendo este ensino teórico e prático. Mas, uma das principais características destacadas nesse estatuto era que o sócio que fosse aprovado nas matérias do "Curso comercial" teria um diploma de habilitação conferido pela Diretoria da associação (ESTATUTOS, 1892).

A associação deveria emitir um diploma para o associado que passasse pelas matérias e que, ao final, conseguisse a aprovação. Não temos certeza do ano de inauguração desse Curso Comercial pretendido pela associação. Temos, entretanto uma pista de que em 1903 o curso estava em vias de entrar em funcionamento.

É pertinente questionar a real necessidade de a Associação abrir um curso comercial se ele já existia em outras instituições de ensino. A justificativa seria o fato do ensino nessas outras instituições ser voltado para indivíduos com a capacidade de financiálas. Era um privilégio para um grupo diminuto da sociedade, não comportando nesse ínterim toda a classe trabalhadora no comércio. ${ }^{3}$ No entanto, não deixamos de levantar a possibilidade de que a abertura desse curso representasse a busca da materialização de um controle da associação em relação ao mercado de trabalho. Ou seja, a partir do momento que ela fosse a responsável pela certificação da qualificação de seus sócios poderia, semelhantemente à Associação dos machinistas, exercer um controle na habilitação de trabalhadores para a ocupação dos cargos disponíveis.

Antes de avançarmos nas discussões sobre as ações que foram desenvolvidas pela Associação dos Empregados no Comércio de Pernambuco, é importante resgatar um pouco da história dos comerciários (os caixeiros), para tanto necessário se faz retomar um pouco dessa história tendo como referencia o século XIX. 


\section{A atividade caixeiral em Recife}

Desde meados do século XIX a classe caixeiral foi responsável por disputas políticas no Recife. O acontecimento denominado "mata-marinheiros" e o crescente antilusitanismo dos trabalhadores no comércio representam marcos importantes para o entendimento da estruturação dessa categoria.

Além da luta pela sobrevivência diária, os trabalhadores estavam fartos de disputarem o mercado de trabalho com os portugueses, pois, dividiam um mercado de trabalho desvalorizado socialmente. Os portugueses vinham de Portugal sabendo ler e escrever o que os tornavam qualificadamente mais demandados para o trabalho no comércio (CÂMARA, 2005; CARVALHO, 1993).

Segundo Lima e Silva (2010), é possível que conflitos tenham ocorrido no interior de estabelecimentos comerciais em virtude das diferenças de funções ocupadas e do nível de escolaridade, seja entre os trabalhadores estrangeiros com os brasileiros, como também entre os próprios trabalhadores nacionais.

Alguns anúncios de jornais desde o século anterior ilustram o interesse de empregadores por trabalhadores vindos do além-mar:

Caixeiro: Precisa-se de um caixeiro português e com prática de molhados, na Rua das Laranjeiras $n^{\circ} 02$ (Diário de Pernambuco, 03 de maio de 1880).

Precisa-se de um caixeiro para taverna, prefere-se português de12 a 14 anos de idade, tratar em frente ao hospital Pedro II, número 21 (Diário de Pernambuco, 05 de janeiro de 1880).

Precisa-se de um rapaz português de 16 anos, para caixeiro de loja de fazendas, com alguma prática no dito estabelecimento: quem dele precisar dirija-se ao armazém do Barros $n^{\circ} 4$ (Diário de Pernambuco, 12 de Janeiro de 1861).

Precisa-se de um caixeiro português, para tomar conta de um deposito de padaria no bairro de Santo Antônio, dando-se metade dos lucros, prestando um bom fiador a sua conduta: a tratar na rua do cotovelo $\mathrm{n}^{\circ} 29 \mathrm{e}$ 31 (Diário de Pernambuco, 14 de janeiro de 1851).

Mas também não é de se desconhecer que também desde meados do século XIX aqueles que já detinham esse conhecimento já se ofertavam direcionando-se para as atividades de escrituração ou de contabilidade. Embora seja possível identificar que nos anúncios a presença de trabalhadores portugueses seja bem evidenciada

Quem precisar de um caixeiro para escrituração, sabendo falar as línguas inglesa, francesa e espanhola, aprendida em seus próprios países: anuncie a sua morada. Previne-se que não tem grande prática de comércio, porque para outros fins estudava, todavia será satisfeita qualquer comissão que lhe for incumbida (Diário de Pernambuco, 23 de janeiro de 1851).

Um moço recentemente chegado de Portugal, com as habilitações necessárias para o comércio, tanto em grosso como a retalho, e tendo sofrível letra, o qual serve também para o serviço de escritório, se oferece aquelas pessoas que dele se quiserem utilizar de seus serviços, e tenham a bondade de se dirigir a rua da Cadeia, loja $n^{\circ} 44$ (Diário de Pernambuco, 22 de Março de 1861)

Oferece-se um rapaz português para caixeiro de venda, para tomar conta por balanço, ou sem ser por ele, para o que tem bastante prática: quem de 
seu préstimo se quiser utilizar, dirija-se a pracinha da Independência $\mathrm{n}^{\circ} 10$, das 10 horas as 2 da tarde (Diário de Pernambuco, 05 de maio de 1851).

Quem disputava esse mercado de trabalho? Eram em sua grande maioria crianças que desde os 7 anos estavam sendo instruídas nos serviços comerciais e aos 14 eram consideradas trabalhadores completos e passíveis de terem seu trabalho explorado.

Eram caixeiros empregados em padarias, para tráfico de rua, para balcão de loja, para secos e molhados, hotel, farmácias, como guarda-livros dentre outros. Mas, a partir da investigação dos anúncios do Diário de Pernambuco e Jornal do Recife entre os anos de 1857 e 1889, Lima e Silva (2010) fazem um alerta sobre o modo como esses trabalhadores eram recrutados, pois, com a crescente diminuição dos anúncios e a baixa diversidade de chefes de diversos estabelecimentos procurando caixeiros, tais trabalhadores poderiam ser recrutados mediantes outras estratégias sociais.

Em outra investigação (OLIVEIRA, 2011) também constatou que a forma como apareciam os anúncios de contratação surgiam das mais diversas formas e estabelecendo também distintas exigências. Vejamos alguns exemplos:

Precisa-se de um rapaz de 12 a 14 anos para caixeiro de venda; no largo da Santa Cruz n 2 (Diário de Pernambuco, 07 de fevereiro de 1851).

Precisa-se de um português de 12 anos, dos chegados ultimamente, ainda mesmo sem prática, para se admitir num depósito de padaria: a tratar na Rua de Hortas $n^{\circ} 18$, ou na rua do Cotovelo n²9 (Diário de Pernambuco, 28 de fevereiro de 1851).

Precisa-se de um caixeiro de idade de 14 a 16 anos, e que afiance sua conduta, se tiver prática de refinação se prefere: a tratar na Rua Direita $n^{\circ}$. 10 (Diário de Pernambuco, 26 de janeiro de 1870).

Precisa-se de um caixeiro que tenha prática de taberna: a tratar na Rua do Rosário da Boa Vista ${ }^{\circ} 41$ (Diário de Pernambuco, 14 de Janeiro de 1861).

Concordamos com Lima e Silva (2010) que, de certa forma, a inserção dos caixeiros no mercado de trabalho apresentava pelo menos duas fases. Na primeira fase o recrutamento poderia ser tanto para caixeiros com prática ou para aprender o ofício - daí a demanda e oferta de crianças entre os 7 e 14 anos. Se fosse para aprender a "arte do comércio' dependia muitas vezes da prática do dia a dia, da observação, de acertar e errar. Provavelmente distribuído dentro de uma hierarquia funcional, ocorrendo com frequência nos grandes estabelecimentos comerciais e nas casas de grosso trato" (LIMA E SILVA, 2010, p. 802). Ou seja, a fase de aprender o ofício era crucial para o pequeno caixeiro elevar-se socialmente, seja para ser empregado num estabelecimento maior e mais promissor, seja para conseguir montar sociedade com seu antigo patrão.

Já na segunda fase o aceite da contratação se dava por meio da cobrança e aceite da fiança de conduta, do ser cobrado e de ser capaz de certificar as suas elevações morais, conseguindo assim uma confiança do futuro patrão. De acordo com a pesquisa de Lima e Silva, o afiançamento de conduta foi caindo em desuso ou modificada no decorrer da segunda metade do século XIX, pois, nos anúncios de jornais foi desaparecendo aqueles que ainda exigiam esta relação quase paternal do antigo patrão ou mesmo, proprietário.

Essa crescente impessoalidade do oficio é perceptível por conta da construção de um mercado de trabalho sobre a égide de um conceito mais liberal e capitalista, mas que não foi o suficiente para encerrar todas as práticas dessa tradição paternalista. Ou seja, os 
caixeiros não precisavam mais ser "conhecidos", "recomendados" e "afiançados", pelo menos, não nos anúncios de jornais.

Voltando especificamente à questão da qualificação profissional, observamos alguns anúncios de professores particulares que ofertavam aulas de matérias comerciais, como a aritmética aplicada ao comércio, atendendo, de certa forma, a uma demanda por uma instrução comercial, no entanto o acesso a esta preparação mostrava-se restrito àqueles com possibilidade de financiá-lo.

Logo abaixo apresentamos exemplos de anúncios demandando alguma formação comercial ou domínio da escrita e da contagem. Em seguida, exemplos de professores ofertando seus serviços para aqueles que almejavam arranjar um emprego de caixeiro.

\section{Oferta de empregos:}

A pessoa que souber bem escrever e com boa letra, querendo se incumbir numa pequena escrituração: apareça na Rua da Cruz do Recife, botica de Luis Pedro das Neves, que achará com quem contratar (Diário de Pernambuco, 12 de fevereiro de 1851).

Precisa-se de um menino de 12 a 14 anos de idade que seja brasileiro com boa letra para caixeiro de escritório: tratar a Rua do Crespo número 25 (Diário de Pernambuco, 26 de janeiro de 1870).

Precisa-se de um caixeiro que entenda de escrituração simples, escreva com ortografia e entenda alguma coisa de mercadorias, para uma casa e loja em Maceió: 68, quem estiver nestas circunstâncias, dirija-se à rua do

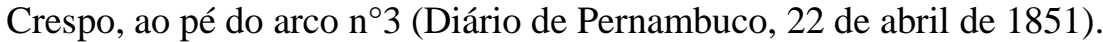

\section{Ensino do Ofício:}

Ensino de aritmética e escrituração comercial do dia 2 de janeiro próximo futuro em diante Mendonça Belém - dará lições de Aritmética aplicada ao comércio, assim como escrituração por partidas dobradas com aplicação não só em casa de negócio e estabelecimentos rurais, como também às repartições de fazenda; e crê o anunciante poder garantir aos seus discípulos estudiosos o maior aproveitamento, afiançando-lhes desde já que lhes ensinará particularidades práticas que tenha esquecido a maior parte dos mestres até agora (...). (Jornal do Recife, 03 de Janeiro de 1865).

Sobre a instrução desses pequenos trabalhadores no comércio só é possível fazer suposições. Já apontamos a possibilidade de professores particulares - para crianças com possibilidade de pagar o ensino particular - e o aprendizado pela própria inserção no universo de trabalho, sem haver um ensino sistemático de disciplinas.

Há a possibilidade dessas condições de trabalho e instrução se modificarem exatamente com o aparecimento da Associação dos Empregados no Comércio de Pernambuco. Voltemos então às ações dessa Associação.

Pela escassez das fontes, analisar os cursos comerciais, tanto o aberto pelo poder público, quanto o da associação é enveredar num terreno difícil e possivelmente andar em círculos. Entretanto, em 1911 houve a inauguração de uma Academia do Comércio fundada e mantida pela Associação dos Empregados no Comércio. Seu estatuto apresenta os cursos ministrados, sua duração e as cadeiras de cada um. Mas, por enquanto vamos no ater ao curso noturno pretendido e não à Academia do Comércio. 
Apesar dos benefícios oferecidos pela associação, uma grande quantidade de trabalhadores no comércio não se associava. Se de acordo com a proposta da associação apenas aqueles que completavam seu curso comercial ou a academia do comércio eram habilitados para exercer o ofício, temos no mínimo 1.157 (Sócios Efetivos) habilitados. Esse valor é passível a aumentar de acordo com os alunos que preferiam realizar o curso comercial em outras instancias educativas. Ainda assim, o total de indivíduos exercendo o ofício de comércio era de 12.775 trabalhadores, ou seja, possivelmente sem habilitação (“desqualificados").

É sobre esses méritos (a abertura e desenvolvimento de cursos de ensino profissional) que a associação passou a requerer frente ao poder público medidas para melhorar as condições de trabalho dos empregados no comércio. A instrução dos associados aparentava ser a chave mestra dessa negociação com o poder público. Mac Cord (2009) quando analisa a Sociedade dos Artistas Mecânicos e Liberais (iniciando suas atividades desde 1836), parece demonstrar concepção semelhante à nossa, pois, é exatamente a partir dos discursos sobre a instrução dos associado-trabalhadores que esta sociedade passou a requerer e negociar com o poder público algumas melhorias nas condições de trabalho, bem como o monopólio de mercado.

Os poderes locais delegavam à associação (iniciativa particular) as atribuições quanto ao ensino profissional, assim a

\begin{abstract}
"mutualista de artesãos recifenses procurou (re) construir a distinção cotidiana de seus membros [...] Artífices como José Vicente Ferreira Barros Junior conseguiram romper barreiras sociais através da instrução, muitos outros trabalhadores assistiram aulas de apoio à prática de seus ofícios (o que agregou valor simbólico à mão-de-obra especializada) e subvenções anuais foram concedidas à associação" (MAC CORD, 2011, P. 17).
\end{abstract}

Não podemos deixar de notar que essa atribuição faz parte, também - e talvez principalmente -, das conquistas dos próprios artistas mecânicos e liberais no Recife.

As experiências e ações dos artífices de cor no Recife, preocupados em instruir e elevar socialmente seus pares garantiu-os o exclusivismo de mercado das construções no Recife para os associados, inibindo a contratação de imigrantes europeus; um fundo público destinado para a associação em auxílio aos vencimentos mensais; pleno envolvimento dos associados com a vida pública da então Província e depois Estado de Pernambuco. E, principalmente, a coordenação do Liceu de Artes e Ofícios inaugurado em 1880 pelos então reminiscentes e descendentes da associação (MAC CORD, 2009).

A negociação da Associação dos Empregados no Comércio de Pernambuco com o poder público é demonstrada no estatuto de 1919. São feitas diversas declarações acerca de como anda o curso comercial e a Academia do Comércio, dos seus benefícios ao Estado, de como a instrução era voltada para a civilização dos trabalhadores, na perspectiva de uma educação pelo trabalho, ou seja, "instruir, fortalecer-lhes o caráter, dar-lhes os ensinamentos necessários à vida prática, equivale a fazer homens - isto é o que a Associação tem feito aos associados e filhos de associados, que todos os anos procuram os cursos mantidos por ela" (RELATÓRIO, 1921, p. 13) e é a partir desse discurso que os associados vêm pedir auxílio público.

É necessário um forte auxílio e, talvez só com auxílio do governo Federal ou do Estadual, possamos levar a efeito tal importante serviço, pois que, 
além da montagem dos escritórios, teremos necessidade de maquinas de escrever e de calcular, prensas de copiar, livros e expediente de professores. De outra necessidade resente-se ainda a Academia e está é a substituição do seu mobiliário. A Academia precisa de um mobiliário apropriado e bastante. Estas necessidades precisam ser satisfeitas, pouco a pouco, porque não dispomos de capital e apesar do grande serviço que a Academia presta ao comércio e quiçá ao Estado, não contamos com o auxílio oficial, com honrosa exceção da Prefeitura Municipal. (RELATÓRIO, 1921, p. 18)

A subvenção municipal contava com 3:000\$000 uma quantia que aos ditames do relatório não dava para comportar um curso de tal magnitude. O serviço que a Academia presta ao comércio e ao Estado é sempre valorizado, tentando através de uma retórica e de resultados convencer o leitor. É por meio dessas informações que percebemos que a instrução era utilizada como forma de negociação frente ao poder público, se ela engrandece o trabalhador qualificando-o, este também merece ser engrandecido pelos benefícios que o poder público deveria oferecer.

Esse jogo econômico entre a associação e o poder público transparece também quando a associação nos fala acerca da regulamentação das horas de trabalho. É um manifesto entregue junto ao relatório para acelerar o processo legal para que haja a regulamentação em 10 horas de trabalho por dia. Mas, não é só isso. Era exigido como direito dos empregados no comércio férias de quinze a trinta dias após o empregado ter trabalhado consecutivamente dois anos; a demissão com aviso prévio do empregador entre trinta a sessenta dias; por fim aos empregados, sem contrato, depois de dois anos de serviço ativo, regular os mesmo direitos e regalias, que aos empregados por contrato registrado (RELATÓRIO, 1921).

Esse jogo de trocas também exercia impacto no próprio discurso da associação, pois, se a educação era um modo de lutar por direitos, a conquista desses direitos teria implicações na melhoria da qualidade da educação e da formação dos trabalhadores associados.

Haveis de notar que, de uma matricula assaz numerosa, bem poucos prestam exames; a razão disto é que, sendo quase todos empregados no comércio, não lhes sobra tempo para fazer um estudo regular; é necessário àqueles que se matriculam, muita força de vontade e um grande esforço para obterem algum resultado. Todos tem desejo de estudar - o que se verifica pela matricula; porém quando vão as lições saindo dos limites da parte comum para a parte adiantada, mais difícil, onde é preciso o estudo acurado, falece-lhes o esforço e abandonam. É possível que, regularizadas as horas de trabalho para o comércio de nossa praça, estas dificuldades desapareçam. (RELATÓRIO, 1921, p. 15-16)

Está se falando sobre a regulamentação de trabalho e da falta de tempo para os jovens caixeiros conciliarem as horas de trabalho com as horas de estudo, pois havia muitas matrículas e na época de exames poucos os realizavam.

Destacamos, a partir dessas informações, duas possíveis dimensões para o "abandono" do curso pelos jovens caixeiros: 1. O fato dos alunos buscarem no curso comercial o ensino que lhes seria útil para a vida prática no emprego, possivelmente as cadeiras de conteúdo idêntico ao ensino de primeiras letras (ler, escrever, e as quatro operações básicas da matemática). Quando o curso passa a trabalhar conceitos menos 
práticos os alunos passam a deixar o curso, pois, o trabalho já lhes cansa bastante e sua preocupação é habilitar-se para o trabalho e somente para este; 2 . A segunda dimensão seria aquela proposta pelo próprio relatório de que a extensão da jornada de trabalho dificultava o aluno permanecer no curso e prestar exames.

Se essas duas dimensões podem ser lidas separadamente, não extingue a possibilidade de ser lida em conjunto e de se lançar aí outra problemática. Se a proposta da associação é englobar o máximo de sócios e estes possuírem a habilitação que os permitiria ser reconhecidos para o trabalho, os alunos que assistem parte do curso e não são diplomados entram (ou permanecem) no mercado sem a carta de habilitação da associação, fazendo com que a proposta da associação não tenha sido implantada tão facilmente. Ou seja, dos 12.775 trabalhadores no comércio, supomos que muitos eram desqualificados, segundo os ditames da associação. No entanto, esses eram os mais contratados para os serviços de caixeiros no Recife.

Portanto, a Associação dos Empregados no Comércio de Pernambuco aparece para a caixeiragem como uma forma de regulamentar sua profissão além de procurar legalizar, frente ao poder público, essa regulamentação. A abertura de cursos noturnos e da Academia do Comércio exemplificou as ações dessa associação voltada para a instrução e qualificação profissional dos seus associados e da categoria profissional como um todo. É um exemplo da atuação das associações voltadas para a classe dos trabalhadores e com a preocupação da negociação de direitos frente ao poder público.

Concluímos ressaltando o fato de que a partir das condições insalubres de trabalho, da disputa por mercado, da falta de reconhecimento social e impossibilidade de subsistir e subvencionar custos básicos individuais, os trabalhadores através de estratégias organizaram-se em associações. Associar-se tinha como objetivos: arcar mutuamente com os custos individuais; buscar salubridade de trabalho; e através das ações em ensino profissional protegerem e tentar monopolizar o mercado de trabalho, chegando até mesmo a abrir cursos superiores que permitiam tal intento.

O caso demostrado da Associação dos Empregados no Comércio é um exemplo, pois, em seus relatórios e estatutos foi possível averiguar as intenções dessa organização em instruir seus associados e os trabalhadores no comércio em Pernambuco, além de por meio dessa "benfeitoria", demandar ao Estado maiores cuidados com a categoria.

Uma dessas exigências foi a regulamentação das horas de trabalho, e se tal fosse aceita ajudaria ainda mais na educação de jovens trabalhadores, pois, estes poderiam dedicar mais tempo aos estudos. Ou seja, a associação estava preocupada com a instrução dos pequenos trabalhadores do comércio recifense, preocupava-se com sua formação profissional, sua qualificação, e tal associação foi também a responsável por tentar modificar as relações de trabalho vivenciadas por esses trabalhadores do comércio.

Assim, nossa principal contribuição, a partir de uma pesquisa ainda em andamento, é mostrar que embora em meados do século XIX tenha sido forte o debate sobre a importância do poder público investir na educação e na qualificação profissional (OLIVEIRA, 2011), foram os próprios trabalhadores os que mais investiram em tal ação. No entanto, é importante mostrar que essas ações de formação profissional apresentavam dimensões também de ordem política. Por um lado, com elas assegurar o monopólio do mercado de trabalho por algumas associações de trabalhadores e, por outro, a conquista de alguns benefícios do poder público.

\section{Referências}


ARRAIS, Raimundo. O Pântano e o Riacho: a formação do espaço público no Recife do século XIX. São Paulo: Humanitas/FFLCH/USP, 2004.

BARBOSA, Alexandre de Freitas. A formação do mercado de trabalho no Brasil. São Paulo: Alameda, 2008.

BATALHA, Claudio H. M. "Sociedades de trabalhadores no Rio de Janeiro do Século XIX: algumas reflexões em torno da formação da classe operária”. Cadernos AEL: sociedades operárias e mutualismo, (1999), volume 6, números 10/11.

Cultura associativa no Rio de Janeiro da Primeira República. In. BATALHA, Claudio H. M. SILVA, Fernando Teixeira da. FORTES, Alexandre (orgs.). Culturas de classe: identidade e diversidade na formação do operariado. Campinas, SP: Editora da Unicamp, 2004.

Limites da Liberdade: Trabalhadores, Relações de trabalho e Cidadania durante a Primeira República. In.: LIBBY, Douglas Cole \& FURTADO, Júnia Ferreira (orgs). Trabalho Livre, trabalho escravo: Brasil e Europa, séculos XVII e XIX. São Paulo: Annablume, 2006.

BELLO, Ruy. Subsídios para a História da Educação em Pernambuco. Recife: Secretaria de Educação e Cultura, 1978.

BERNARDES, Denis. Recife: o caranguejo e o viaduto. Recife: Editora Universitária da UFPE, 1996.

CÂMARA, Bruno Augusto Dornelas. Trabalho livre no Brasil imperial: o caso dos caixeiros de comércio na época da Insurreição Praieira. Dissertação de mestrado. UFPE, 2005.

CARVALHO, Marcus J. M. Liberdade: Rotinas e rupturas do escravismo. Recife, 18221850. Recife: ed. Universitária da UFPE, 1998.

CARVALHO, Marcus J.M. O antilusitanismo e a questão social em Pernambuco, 18221848. In. Miriam Halpern Pereira (organizadora). Actas do Colóquio Internacional sobre Migração e Imigração em Portugal (séc. XIX e XX). Editora Fragmentos, Lisboa, Portugal, 1993.

FONSECA, Celso Suckow da. História do ensino industrial no Brasil 1 . V. 1. Rio de Janeiro: SENAI/DN/DPEA, 1986a.

GONDRA, José Gonçalves \& SCHUELER, Alessandra. Educação, poder e sociedade no Império Brasileiro. São Paulo: Cortez, 2008. (Biblioteca básica da história da educação brasileira).

LIMA, Dayana Raquel Pereira de. \& SILVA, Adriana Maria Paulo da. Trabalhadores do comércio: a atuação dos caixeiros no recife entre 1857 a 1889. Paraíba, UFPB: Anais Eletrônicos do II Encontro de História do Império Brasileiro: culturas e Sociabilidades: Políticas, diversidades, identidades e práticas educativas, 2010.

MAC CORD, Marcelo. Andaimes, casacas, tijolos e livros: uma associação de artífices no Recife, 1836-1880. Campinas, São Paulo: Unicamp, 2009. (Tese de Doutorado).

MAC CORD, Marcelo. Artífices de cor do Recife: dos privilégios corporativos à tentativa de controle da escolarização dos ofícios décadas de 1840 e 1850. CLIO. Série História do Nordeste (UFPE), v. 28, p. 1-24, 2011. 
MELlO, Evaldo Cabral de. "Canoas do Recife: Um Estudo de Microhistória Urbana". Revista do Instituto Arqueológico, Histórico e Geográfico Pernambucano. (1978). Vol. 1.

MELLO, Evaldo Cabral de. O Norte Agrário e o Império 1871-1889. Rio de Janeiro: Toopbooks, 1999.

NEGRO, Antônio Luigi \& GOMES, Flávio. Além das senzalas e fábricas: uma história social do trabalho. Tempo Social revista de sociologia da USP, v. 18, n.1, 2006.

OLIVEIRA, Ramon de; SILVA, Adriana Maria Paulo da. Relatório de Pesquisa: Demandas por qualificação profissional: Recife, segunda metade do século XIX. Recife, 2010. Financiado com recursos do CNPq.

OLIVEIRA, Ramon. Demandas por qualificação profissional: Recife, segunda metade do século XIX. In. Reunião anual da ANPED, 34., Natal. Anais, Educação e Justiça Social. Rio de Janeiro: ANPED, 2011. p. 1-16.

PRADO JÚNIOR, Caio. História econômica do Brasil. 16 ed. São Paulo: Brasiliense, 1973.

SANTOS, Yan Soares; OLIVEIRA, Ramon de. Relatório de Pesquisa: Ações de trabalhadores e do patronato recifense no campo da qualificação profissional, entre os anos de 1889 e 1930. Recife, 2011. Financiado com recursos da CNPq/Facepe.

SILVA, Adriana Maria Paulo da. Processos de construção das práticas de escolarização em Pernambuco, em fins do século XVIII e primeira metade do século XIX. Recife: Editora Universitária da UFPE, 2007.

SINGER, Paul. Desenvolvimento econômico e evolução urbana (análise da evolução econômica de São Paulo, Blumenau, Porto Alegre, Belo Horizonte e Recife). (2 ${ }^{\mathrm{a}}$ ed.) São Paulo: Cia. Editora Nacional, 1977.

\section{Fontes Primárias}

ANÚNCIOS do Diário de Pernambuco anos: 1890; 1910; 1920; 1930 - Setor de Microfilmagem - Fundação Joaquim Nabuco - Fundaj.

DIRETORIA Geral de Estatística. Estatística da Instrução. Estatística Escolar. v. I. Rio de Janeiro: Typografia Estatística, 1916.

DIRETORIA Geral de Estatística. Annuário Estatístico do Brasil1º anno (1907-1912) V. III cultos, assistência, repressão e instrução. Rio de Janeiro: Typografia Estatística, 1927.

DIRETORIA Geral de Estatísticas. Recenseamento do Brazil. V. V. Indústria. Rio de Janeiro: Typografia Estatística, 1920a.

DIRETORIA Geral de Estatísticas. Recenseamento do Brazil. V. IV. Predial. Rio de Janeiro: Typografia Estatística, 1920b.

ESTATUTOS da Academia do Comércio de Pernambuco. Pernambuco: Tipografia do Diário de Pernambuco, 1911. (APEJE: Folhetos Raros II).

ESTATUTOS da Associação dos Empregados no Comércio de Pernambuco. Pernambuco: Tipografia do Jornal do Recife, 1892. ( APEJE: Folhetos Raros II).

ESTATUTOS da Associação dos Empregados no Comércio de Pernambuco. Pernambuco: Tipografia do Jornal do Recife, 1903. (APEJE: Folhetos Raros II). 
FUNDAÇÃO Instituto Brasileiro de Geografia e Estatística. Estatísticas Históricas do Brasil. Rio de Janeiro: IBGE, 1990.

RELATÓRIO da Associação dos Empregados no Comércio de Pernambuco relativo ao ano de 1919. Pernambuco: Imprensa Industrial, 1921. (APEJE: Folhetos Raros II).

INSTITUTO Nacional de Estatística. Anuário Estatístico do Brasil. Rio de Janeiro: Tipografia do Departamento de Estatística e Publicidade, 1936.

\section{Notas}

${ }^{1}$ Licenciado em História pela Universidade de Pernambuco e Mestrando em Educação pela Universidade Federal de Pernambuco - Universidade Federal de Pernambuco - UFPE

${ }^{2}$ Doutor em Educação. Professor do Programa de Pós-Graduação em Educação - UFPE - Universidade Federal de Pernambuco

${ }^{3}$ Há a possibilidade de esse curso estar baseado no curso comercial, implementado na província de Pernambuco entre 1863 e 1867, tendo este três cadeiras: 1. Noções gerais de Comércio; 2. Contabilidade e prática das operações comerciais; 3. Princípios de Economia Política relativos ao comércio e Direito Mercantil. Tal curso não teve um grande número de inscritos, muito menos continuou a ser frequentado, deixando de existir quatro anos após sua inauguração. Houve um curso de comércio também no Instituto Benjamin Constant, mas este instituto só durou até 1899. O Ginásio Pernambucano também tinha um curso comercial como demonstra a bibliografia. Cf. OLIVEIRA, Ramon de; SILVA, Adriana Maria Paulo da. Relatório de Pesquisa: Demandas por qualificação profissional: Recife, segunda metade do século XIX. Recife, 2010. Financiado com recursos do CNPq; Cf. BELLO, Ruy. Subsídios para a História da Educação em Pernambuco. Recife: Secretaria de Educação e Cultura, 1978. p. 128-129.

Recebido em

outubro-2012

Aprovado em

fevereiro-2013 